\title{
Emotional Meanings Assigned to Eating Disorders: Narratives of Women with Anorexia and Bulimia Nervosa
}

Leonidas $\mathrm{C}^{1}$ and dos Santos $\mathrm{MA}^{2 *}$

'Department of the Federal University of Triângulo

Minera, University of São Paulo, Brazil

${ }^{2}$ Department of Psychology, University of São Paulo, Brazil

*Corresponding author: Manoel Antônio dos Santos, Department of Psychology, University of São Paulo, Faculty of Philosophy, Sciences and Letters of RibeirãoPreto, Bandeirantes Avenue, Monte Alegre, São Paulo, Brazil

Received: J anuary 30, 2017; Accepted: February 21, 2017; Published: February 23, 2017

\begin{abstract}
This study aimed to investigate emotional meanings assigned to Eating Disorders (ED) through narratives of women affected with these psychopathological conditions. Participants were patients in a Brazilian service specialized in treatment of ED. A semi-structured interview was used for data collection. Recruitment continued until data saturation was reached. The verbatim transcription of interview data was analyzed through thematic content analysis, which was employed by two researchers. Results showed that, after the occurrence of ED, participants began to experience feelings of distress, anxiety and loneliness, which were related to lowered self-esteem and social isolation. Family dynamics was characterized as confrontational, but in contrast, was considered participants' primary social support network. These data underlined that the emotional meanings attributed to ED need to be addressed and explored by health care professionals to gain a detailed understanding of patients' illness experiences.
\end{abstract}

Keywords: Eating disorders; Narratives; Family

\section{Introduction}

According to DSM-V [1], Eating Disorders (ED) can be characterized as psychopathological conditions that involve serious disturbances in eating behavior and affect mostly teenagers and young women. These disorders present a chronic and disabling progress, and can result in biological, psychological and social damages that cause increased morbidity and mortality. They affect a wide age range - usually between 13 and 21 years - and may have a fatal outcome if not treated, depending on the seriousness of the disease or the consequences of health problems. They are prevalent in women of all social levels, being the third most common mental disorder among women [2].

Anorexia Nervosa (AN) and Bulimia Nervosa (BN) are the two most prevalent types of ED. AN may be characterized as a refusal of the individual to maintain appropriate body weight to their age and height, an intense fear of gaining weight and a significant disturbance in the perception of shape or size of the body, resulting in cachexia [1]. Regarding the aspects of personality of AN patient, several authors cite inferiority, inadequacy and insecurity, perfectionism, obsessiveness, compulsiveness, negative emotions, withdrawal and avoidance behaviors [3,4]. Cooper, Deepak, Grocutt and Bailey suggest that the experience of "feeling fat", intensely experienced by patients with ED, seems to be related to a combination of factors such as anxiety, internal and external bodily sensations, feelings rejection, social exclusion, and negative beliefs about themselves [5].

According to patients' reports, the onset of ED is usually associated with the occurrence of a stressor event: critical comments about weight end of a love relationship, loss of a loved one, and other traumatic events. Then, the individual begins to live in relation to the diet, the concern about their weight and body shape, physical activities, calories' tables and pathological fear of fat [4]. This kind of obsessive thinking leads to a very strict discipline in performing diets, which success leads to feelings of control [6].

In contrast, BN involves recurrent episodes of binge eating, feelings of loss of control over eating during the binge episodes, and recurrent inappropriate compensatory behaviors such as vomiting, use of laxatives, diuretics and metabolism stimulant medications, excessive physical exercises, among others [1]. The disorder is also associated with impulsive behaviors and comorbidities, such as histrionic personality disorder traits and borderline type $[7,8]$, a floating self-esteem and maladaptive thoughts and emotions. It is common to find evidence of chaotic attitudes, not only regarding to eating habits, but also in other aspects of life such as studies, work and romantic relationships [8].

The typical exaggeration of patients with BN usually occurs in the form of private and solitary acts, and configures an attack to cooking, to education and to moral behaviors, subverting biological needs of the hunger and contesting what is ethically and aesthetically accepted, as well as rules, uses, learning's and the social dimension of eating [8]. From brandished attacks, arise moral disapproval and shame experienced by individuals affected by these conditions.

Regarding to psychological functioning, women with BN have a number of maladaptive thoughts and emotions regarding their eating habits and their body weight. Moreover, they also have unstable self-esteem and believe that a well-designed body would solve their problems of personal insecurity. To accomplish the idealized body, these women perform excessive diets, purging rituals and strenuous exercise. Thus, the desire to lose weight seem to be associated with personal disorganization, in which regulation and control over eating can be considered as an attempt to organize and stabilize the chaotic mental state [8].

According Frosthlom [9], patients' perception about their 
Table 1: Participants' characterization according to age, diagnostic, weight, height, admissional BMI, current BMI and time of treatment.

\begin{tabular}{|c|c|c|c|c|c|c|c|}
\hline Participants & Age (years) & Diagnostic & Weight (kg) & Height (m) & Admissional BMI $\left(\mathrm{kg} / \mathrm{m}^{2}\right)$ & Current BMI $\left(\mathrm{kg} / \mathrm{m}^{2}\right)$ & Time of treatment (months) \\
\hline Mary & 30 & Purging AN & 49,1 & 1,64 & 17,8 & 18,3 & 22 \\
\hline Christy & 20 & $\mathrm{BN}$ & 59,3 & 1,65 & 23,5 & 21,9 & 10 \\
\hline Heather & 27 & $\mathrm{BN}$ & 63,4 & 1,75 & 21,2 & 20,6 & 12 \\
\hline Sophie & 27 & Purging AN & 44,1 & 1,72 & 14,7 & 14,9 & 6 \\
\hline Barbara & 24 & Purging AN & 56,4 & 1,60 & 21,9 & 21,9 & 1 \\
\hline Caroline & 31 & $\mathrm{BN}$ & 101,3 & 1,65 & 36,1 & 37,2 & 84 \\
\hline Florence & 40 & Purging AN & 70,8 & 1,74 & 16,7 & 23,2 & 184 \\
\hline Amber & 22 & Purging AN & 50,8 & 1,66 & 17,3 & 18,4 & 48 \\
\hline July & 30 & Purging AN & 53,3 & 1,67 & 20,4 & 19,1 & 168 \\
\hline Megan & 29 & $\mathrm{BN}$ & 60,7 & 1,69 & 20,0 & 21,5 & 60 \\
\hline Holly & 28 & Purging AN & 47 & 1,71 & 15,9 & 15,9 & 1 \\
\hline Anne & 24 & Purging AN & 40,6 & 1,52 & 15,7 & 17,5 & 60 \\
\hline
\end{tabular}

psychopathological condition is quite relevant and should be taken into account in medical decisions. Their own ideas and concepts about the disorder may provide subsidies for the expansion of biopsychosocial models, contributing to the reduction and/or prevention of the development of chronic diseases.

Listening to patients' perceptions about the ED is needed in scientific research as well as in health assistance, since their narratives constitute the legitimate instrument of communication of emotional experiences [10]. Individual's narrative is the professional's most palpable tool to access patient's difficulties and internal conflicts. The bond between individuals and their "anorexic voice" could explain their ambivalence to change [11]. Hoskins describes a narrative of one woman's reconstitution of self while recovering from anorexia nervosa. Narratives are understood as expressions of the self and the living experience for the individual who narrates $[10,12]$.

The present study aimed to investigate the emotional meanings assigned to ED through narratives of women affected with these psychopathological conditions, in order to understand the emotional experiences involved in living with $\mathrm{AN}$ or $\mathrm{BN}$.

\section{Method}

A qualitative approach was used once the study sought to establish the perspectives of those with ED. The collective case study [13] design was used, since the study involves, in general, the description of experiences of women who are part of a specific group, the ED.

\section{Participants}

This research included 12 women who were in treatment for ED at Assistance Group on Eating Disorders (GRATA), from Clinics' Hospital, Faculty of Medicine of RibeirãoPreto, and University of São Paulo, Brazil. As presented in Table 1, the average age of participants is 27, 7 years. Eight of them were diagnosed with purging type AN, and four of them with BN. Anthropometric data presented in Table 1 was obtained from hospital records. To prevent participants' identification, names were replaced by fictitious ones.

During the period of data collection 15 patients were attending the service, 12 diagnosed with AN and three with BN. Recruitment continued until data saturation was reached, a criterion commonly adopted in qualitative research [14]. This criterion advocates that the optimal number of subjects is achieved to the extent that responses begin to show repetitions when new participants are added to the study, not implementing new information that might be useful and relevant to achieving study's goals.

\section{Instruments}

The instrument used was a semi-structured interview script, which allows the deepening in a particular research topic, over passing a superficial conversation to a rich discussion of thoughts and feelings [15]. The script was composed by the following themes: 1) demographic data; 2) information about the ED; 3) information regarding treatment; 4) participants' emotional situation; 5) the outcome of the interview.

\section{Procedure}

This study was approved by the Ethics Committee of the Clinics' Hospital of the Faculty of Medicine of RibeirãoPreto, University of São Paulo, Brazil (HC-FMRP-USP), and case number HCRP 2010/2155.

Instrument's application was conducted with each participant individually, in face to face situation, at a private room in the hospital, with appropriate conditions of comfort and privacy. The interviews lasted about 60 minutes and were recorded by an MP3 device, ensuring greater data reliability. The interviews were transcribed in full, respecting the sequence and the way the sentences were expressed. This material constituted the research corpus and was subjected to analysis on thematic content [16], which aims to overcome the manifest content to achieve the latent content. Thematic analysis was employed by two researchers. Data were organized into categories and subcategories of analysis, taking into account the regularity of responses and convergent contents of the reports.

\section{Results and Discussion}

Analysis of the data produced five broad thematic categories, which are described and discussed below. It is noteworthy that categories' and subcategories' designations were defined from the joint thematic regularities present in participant's 'narratives. 


\section{Circumstances prior to ED}

This first category concerns the social circumstances in which participants lived before the occurrence of ED. Four participants reported that they used to relate to friends from school, work, and also with friends from childhood, maintaining frequent contact. However, it was noted that such contact was not significant, since participants were characterized as quiet and retract throughout life. Florence and Caroline reported that they "always were [people] of few friends," always preferring to be alone, indicating the existence of scarce social networks. Thus, it was evidenced that traits of introversion, shyness and avoidant behaviors were present in participants' emotional dynamics.

Regarding leisure activities before the occurrence of ED, all participants reported the habit of going to shopping centers, bars and cinema, except for Florence. She considered that she "has a personality of not having many friends", and confided that she never had leisure activities and felt good about it, would not want it to be different. It was possible to note that participants' social lives involved a relatively large number of members in their network with whom they performed some activities.

Personality traits mentioned by participants during interviews (introversion, withdrawal, preference for solitude, among others) support scientific literature, which suggests that the personality of women with $\mathrm{AN}$ is usually marked by traits of inferiority, inadequacy and insecurity, perfectionism, obsessiveness, compulsiveness, negative emotions, withdrawal and avoidance behaviors [3,4]. Women with BN, such as Heather, Caroline and Christy, usually show impulsive behaviors, histrionic traits and borderline personality disorder [7], and maladaptive thoughts and emotions, which often result in chaotic attitudes that undermine many aspects of life, such as studies, work and romantic relationships [17].

Given these assumptions, it is inferred that participants' aspects of personality, apprehended in the interviews and also suggested by the literature, exert crucial influence on participants' difficulty in establishing links with people from their social environment. Withdrawal and introversion, as well as impulsive behaviors and chaotic attitudes, seem to cause difficulties in interaction, resulting in shortage of members of social networks [17] and also in prevention of leisure activities. Considering the relationship between social interactions and quality of life [18], the shortage of members in participants' network and the lack of leisure activities might have close relationship with the Chronicity of the ED.

\section{Meanings related to the onset of the disorder}

This category deals with the factors that participants consider crucial to the onset of the ED. They are: lowered self-esteem and a series of stressful events.

Lowered self-esteem: Many authors [4,19] point out that the impairment of self-esteem is an outstanding feature of the mental functioning of women with ED. The analysis of the interviews corroborated the literature, since participants' reports presented very significant traces of lowered self-esteem. This data item can be illustrated by the narrative of three participants who mentioned the habit of making comparisons between themselves and others, namely mother and sisters, the boy who one of them was in love, friends and girlfriends from ballet. Importantly, these comparisons always culminated in a sense of inferiority on the part of participants, i.e., they always considered themselves at a disadvantage compared to others.

Barbara reported that she had the desire to be like her mother and sister, who she considers "puny" Moreover; the young man who was Barbara's "first love" started dating a girl who, according to the participant, was very thin. By doing these types of comparisons, the participant mentioned feelings of inferiority, which culminated in damages to her self-esteem.

[...]You start having losses, then you start to associate: "Wow, is it because I' $m$ fat?" [...] But then you get, you know, to associate it, then I started liking a boy at the time, there is always that first boy you like, you know?... All of a sudden the person doesn't want to even look at your face, don't want to talk to you, you see him with a super skinny girl, and then you start to associate it all, you know... (Barbara).

Sophie, in turn, reported that her mother and sisters "lived dieting" because "they were chubby". She presented an intense fear of being like them and, along with a diagnostic of depression - in which Sophie experienced thoughts and desires related to death and to "disappear little by little" -, that was the primary reason that led to start food restriction. However, even after severe weight loss, participants' self-esteem had been increasingly lowering and she was still feeling bad about herself and her body. Christy, on the other hand, used to hear from people that she "didn't have the body of a ballet dancer", and she was "shaken" when she heard comments like those. In addition, participant mentioned that she suffered a lot of pressure to lose weight because, she said, "most girls were skinny".

Considering that participants' dissatisfaction is not, at first, a dissatisfaction with the body itself, and that thinness is a social symbol of beauty and success $[3,4,20]$, it is hypothesized that women with ED experience dissatisfaction with themselves in a broader sense, which seems to have been redirected to the body in an attempt to compensate for weakened psychic aspects or to get sense of control over themselves.

Series of stressful events: Sweetingham and Waller point out that the occurrence of adverse experiences - which can also be denominated as stressful events - is considered one of the factors that interact in a complex way and precipitate the ED. Such events may include: bullying, derogatory comments about one's weight, breakups, loss of a loved one, and separation from parents, among others. It was evidenced that the narratives of eight participants in the present study encompassed such events, which will be described below.

In Mary's case, teenage marriage and early separation seemed to be associated to the onset of the ED. Participant reported that the relationship was very conflictual, once her ex-husband "didn't accept her way, her personality." However, she remained silent when questioned about her adolescence, restricting answers only to: “[...] many things have happened, I cannot exactly connect [the ED] to anything". For Barbara, the loss of close people - who, according to her, walked away to "follow their own paths", and not for reasons related specifically to her - along with the derogatory nicknames she received from her sister and school friends during childhood and 
pre-adolescence -she was called "chubby" - exerted influence on the installation of the disorder. The sum of these factors that Barbara named as "losses", was associated with weight and body shape, as she started using weight loss as a means to prove something to people: "I wanted to show others that I was capable". Comments about weight were also mentioned by July as factors related to the onset of ED, mainly because such comments had been made by her own father.

Christy reported that she felt overloaded and suffocated by her father since childhood, which seems to have generated feelings of distress and anxiety that the she "discounted" in overeating and seeks relief in purging through vomiting. However, it was noticed a self-directed overload by Christy, i.e., it was not only her father who overloads her, but she also overloaded herself: she considered that she needs to be skinny for ballet, to work well at her parents newsstand, and she could not spend money because her parents owe a large amount of money. Her parents' debt seemed to have been the stressor that developed the ED, since the overload - both by father and herself - was intensified.

Husband's infidelity (Megan) and the end of a long-term relationship (Holly) also emerged as events that led to the onset of the ED. Holly confided a number of arguments between her and her exboyfriend that culminated in separation, which made her feel very sad and with low self-esteem, arousing the desire to lose weight. Megan, in turn, reported that when she discovered her husband's infidelity, she concluded that weight loss would be a way to get him interested in her again.

I thought, well, I loved him too much, I didn't want to lose him, I imagined that because he cheated on me with my cousin, and my cousin was like, well, skinny, I was never fat, I always had this body, but I thought so: "Wow, he likes very thin women, so if I stay as skinny as her, he will never leave me, will not leave me". So that's where I started eating and purging, dieting, and then I started taking a lot of medicine took a lot of tea, that's how it all began (Megan).

Finally, Florence reported that she has always lived with her grandmother in a distant state, but she had to live with her parents at 19 years of age. At that time, she worked overnight in a hospital and, according to his narrative, she started to binge. She could not appoint the factors that she considered responsible for the onset of the ED, but she mentioned this period of changes in her life as a possible factor of influence on the development of her psychopathological condition.

\section{Experiences and difficulties aroused by the disorder}

This category refers to facts and difficulties which are nowadays experienced by participants as results of the ED. These experiences include: ambivalence between wants and needs, discomfort with people's judgment, recurrent thoughts about food and "roller coaster" of emotions.

Ambivalence between wants and needs: Three participants reported experiencing feelings of ambivalence towards food and eating since the onset of the ED. Such ambivalence regards biological and physiological needs to eat, against the desire to lose weight, which implies the act of feeding in a very restrictive way. Participants narratives involved themes as internal pressure and constant struggle against themselves, which aims to exert self-control and deny hunger.
When self-control does not prevail, all participants, except for Sophie, report a very significant intake of food in a short period of time. According to the DSM-V [1], such food intake can be characterized as binge eating. Packets of biscuits, chocolate boxes, pots of beans, among others, are ingested. According to participants' reports, binge eating is usually followed by feelings of guilt for being aware that the ingested food will fatten them, and for not being able to control their own gluttony.

Discomfort with people's judgment: The act of hiding the ED from people emerged in reports, as result offer of being criticized. Participants described that people around them used to express their opinions in a very inadequate way, leading participants to hide their health condition. Christy's case illustrates the type of comments that participants considered inadequate: she used to dance ballet and expressed desire to be thin to have a "ballerina's body". However, although she did not consider herself overweight, Christy felt very distressed when she heard comments like: "Are you a dancer? You don't have the body of a dancer". When reporting this event, she was fairly distressed, demonstrating the negative impact that people's comments can exert on one's emotions [21].

Caroline reported that "people never come to help you, they come to criticize you". In other words, she believed that people tended to express their opinions only with the intention to nurture negative feelings, and therefore she preferred to hide the ED. Heather thought that the uncomfortable feeling she felt with the judgment of others came from the shame regarding the act of vomiting: she reported that vomiting was "disgusting", and that "it aroused disgust in people". Sophie, in turn, expressed her annoyance through the description of support groups which she participated when she was admitted to the Day Hospital: she considered that the group members did not understand that ED "is a disease, something she has no control over". Therefore, Sophie had much difficulty to join groups and, while attending, she remained silent.

Considering the difficulty that women with ED present in terms of interpersonal relationships [3,4,22], it is hypothesized participants' limitation to question and argue with people when judgment about themselves is exposed. Introversion and avoidance behaviors, which are typical of women with AN $[3,4,23]$, seem to lead participants to put themselves in a passive position when facing negative comments. It is believed that such avoidance reactions to judgment of others can result in social distancing from people, restricting the size of participants' social networks.

Recurrent thoughts about food: It was evident in participants' narratives that food seemed to take up various dimensions of their lives, since it was present not only during meals, but also in social meetings with friends and family, in participants' minds during classes, at work and in many other activities. Six participants reported feeling "persecuted" by food, i. e., they felt as if food was always present, not letting them forget it.

Mary confided that she fought daily against food because she was aware that it was necessary to survive, but, nevertheless, she did not want to eat due to the fear of gaining weight. She reported that these "fights" happened all the time, since food took up nearly all her thoughts, and she needed to push them away. In addition, there was 
also the external pressure from family so that the participant feed, which intensified the difficulty to "win" these "struggles".

Oh, it was very difficult, I couldn't... It was a constant struggle because I looked at food and I didn't... I didn't want to eat because I knew... Even if I ate the smaller piece...That would have fattened me, so it was a constant struggle... It was even a fight (Mary).

Christy and Heather narrated similar feelings regarding the role of food in their lives: both reported that food constituted the majority of their thoughts, once they used to evaluate the caloric intake of all foods and make sure that they would not gain weight when performing certain tasks (such as: eating certain food, or even leaving the house, going shopping, etc). Christy reported that the food "chased her" even in dreams, when she dreams to eat nonstop. The feelings experienced by both participants were described as anguish and "torture".

However, it was noted that such feelings were not related only to food itself - for example, regarding caloric intake - but also to what it represents. Florence and Christy's narratives demonstrated that food may serve as a way to cope with intense emotions, and that it can be swallowed or discarded, depending on the need of the person who handles it.

It was very sad, you know? Very sad... And well, I had this symptom, when I was... Starting to get into compulsion I started having anxiety attacks... Anxiety, much anxiety, suddenly I would get like... It... Anguished, you know? Sad... All these symptoms... And I needed to eat a lot... And eat... Vomit... Eat... Vomit... (Christy).

Thus, participants reported that when they felt sad and distressed, they "needed to eat a lot", "eat endlessly without knowing what they wanted". Vomiting was observed as relief from anxiety, since participants' could "put it [food/anguish] out".

Not being able to leave the house because of the ED also emerged as a difficulty to three participants. They avoided attending social events because they knew they could not eat, or that they would have to create tactics to induce vomiting without anyone noticing. Accordingly, leisure activities with people from their environment were impaired.

"Roller coaster" of emotions: By analyzing participants' major difficulties regarding feeding, it was noted that five of them mentioned mood swings, which were followed by periods of increased binge eating and purging behaviors: three participants reported that when they were "very nervous", anxious and/or distressed, they ate larger quantities of food and performed rituals of purging more frequently. Sophie reported that "there were phases when she felt good about herself and she could eat different things than, but there were also phases when she could not eat anything". Florence believed that she was recovering from the ED and, therefore, she presented less mood swings. She attributed this recovery to psychotherapy and medication.

Florence and Sophie reported that going to hospitals on a weekly basis and the impossibility to perform activities that they performed before the occurrence of the ED - mostly working and/or studying - aroused feelings of incapability that accentuated anxiety and depression. Florence mentioned that she was downgraded in her job position due to impairment of her health condition, once she presented difficulties to perform activities that she used to perform.
This downgrade made her feel devalued and she believed that it intensified the symptoms of ED.

It was evidenced those negative feelings that characterize participants' mood swings - among them: negative self-assessment, feelings of incapability and anxiety for being seen as incapable by others- are typical of individuals with low self-esteem. Karpowicz, Skärsäter and Nevonen [24] suggest that food restriction and purging behaviors are secondary to the primacy of emotional factors in the etiology of ED, especially self-esteem. These authors point out that low self-esteem causes feelings of loneliness, depression and anxiety, i.e., the experience of comfort with oneself and one's body can be regarded as a central element of the individual's welfare. Considering that participants' self-esteem is significantly low, it is believed that most episodes of binge eating and purging behaviors are closely related to emotional factors, which are directed towards the relationship with the body and consequently to feeding.

\section{Feelings experienced after the onset of ED}

Category four concerns feelings that participants reported having experienced more frequently since the occurrence of he ED. Mentioned feelings were: anguish, emotional pain and anxiety; loneliness, sadness and emptiness.

Anxiety emerged as central element in the narrative of five participants. Barbara reported that feelings of distress and anxiety were related to the pursuit of something that she did not know what it was, but she believed that weight loss could help her achieve it.

I don't know, it seems like... You seek something like... That you... At the same time I don't know what it is, you know? I look for something as if it was the perfect solution for my life, but at the same time I don't think it is... [...] And I think that this anxiety, this anguish, you know... That's exactly why, you're looking for something and you don't know what it is. (Barbara).

Florence described that episodes of binge eating were also related to feelings of distress and anxiety. However, she could not distinguish whether these feelings came before or after the episodes, once she experienced various negative emotions at the same time, along with an intense desire to eat and vomit. Christy, in turn, reported that feelings of distress and anxiety were constant in her life, but they were intensified when she thought about stressful situations: family conflicts, feeling suffocated by her father, not being able to leave the house, etc. She believed that she "put distress on food", because the following vomiting enabled a sense of relief from negative emotions.

The feeling of "being alone even in a crowd" was mentioned by Caroline, Heather and Sophie, along with intense feelings of sadness and emptiness. Sophie described these feelings as "a void that can never be full filled", while Heather, July and Caroline, in contrast, reported that "food fulfills them": Caroline feels "warmth and satisfaction" after eating; Heather reported that she felt an emptiness that she did not know what it was, and despite her attempts to distract herself- which included going out and performing physical activities -, she ended up eating excessively, trying to appease the emptiness. However, it was noted that binge eating was only a momentary filling, since they were recurrent episodes. In other words, the void reappeared even after binge eating. 
Florence also mentioned the feeling of emptiness and the difficulty to explain it, describing it only as "a horrible empty feeling" that caused intense suffering. However, her feeling of loneliness was related to a difficulty in establishing social contacts, which restricted the number of members $n$ her social network and also impaired her possibilities of social interaction. In a similar way, Barbara also related the feeling of loneliness as a result from social isolation. She reported that she pulled away from her school friends after the onset of the ED and gradually started to isolate herself from all social networks.

\section{Expected changes}

The present category concerns changes that participants expected to happen, both regarding the ED as other aspects of their lives, such as social relationships, emotional and professional activities, among others. However, when asked about these changes, most participants mentioned aspects related only to family relationships.

Several authors $[16,25-27]$ characterize family social network as the main source of social support for individuals with ED. Hypothesizing the existence of a relationship between vulnerable family functioning and the emergence or perpetuation of the disorder [28], it is considered that changes in relationships and family dynamics are necessary for the improvement of the psychopathological condition.

Among the changes desired by participants were: more dialogue, closeness and affection between family members; fewer conflicts between siblings; greater family participation in treatment; more family togetherness; less critical comments. Three participants had no expected changes, reporting that they were satisfied with their lives and social relationships.

Oh, I always missed a father and a mother, I mean... I don't mean present, because they are present, but I miss a father and a mother, I miss being held in the lap, you know? I miss affection, things I never had... Even when I was a child, because there were always fights and arguments, so I never had mother's and father's affection. I miss it nowadays, it didn't bother me before, but today it's something that I miss... To get affection (Anne).

Oh, I wish that there was more... More conversation, you know? That we could talk, exchange... Exchange experiences, opinions... Things that they like, things that I like, you know? I think that's it, I don't like these threats... That's very bad (Barbara).

Scientific literature on ED points out that families are marked by disharmony, trauma histories, confusing patterns of communication and lack of consistency in responding to daughter's disorder $[25,29,30]$. Furthermore, Dallos and Denford [31] suggest the predominance of problematic ties among family members, which encompass frequent arguments, discomfort and negative relationship with food. Mentioned authors propose that these aspects of family dynamics can be considered precipitating factors of the disorder.

However, despite all family conflicts reported by participants and highlighted by the literature, the fact that participants expressed the desire to change family dynamics points to a central role of the family as a social support network. It is believed that participants considered family as the center of their interpersonal influence, and would like relationship patterns could become healthier, contributing to the improvement of the ED.

\section{Conclusion}

This study aimed to investigate the meanings assigned to ED through narratives of women affected by these psychopathological conditions, seeking to understand emotional experiences involved in the experience of living with AN or BN. It was evidenced that after the onset of symptoms, participants began to experience intense feelings of distress, anxiety and loneliness, which were mainly related to lowered self-esteem and social isolation.

Most participants related the onset of the ED to a number of negative events, named stressors, which encompassed: marriage and/or marital separation, parental separation, breakup, husband's infidelity, family debts, among others. Such events generated intense suffering, unbearable for the psyche and impossible to be emotionally digested. Thus, the affects generated as results of such events appear to have been ejected from consciousness and directed to the body, as participants attempted to maintain their integrity and identity.

Family emerged as the main source of social support, even though relations were marked by conflicts and arguments, in a context of vulnerability. Considering the close relationship between family dynamics and the maintenance of ED, participants presented expectations for changes in family relationships, believing that these changes could contribute to recovering from the psychopathological condition. These changes included: more dialogue, closeness and affection in relationships, less fraternal conflict, greater family participation in treatment and greater family unity. Thus, it is evident the need to include family in treatment of ED, aiming to work family dynamics and, consequently, promote patients' recovery. This upgrading in health assistance would result in improvements in patients' quality of life, since quality of life is closely related to quality of social relations. Interventions that address these components of the ED experience could prove fruitful in helping people towards recovery.

\section{Acknowledgment}

Authors wish to thank São Paulo Research Foundation (FAPESP) for funding this research, process number 2010/01257-7.

\section{References}

1. Arlington. American Psychiatric Association. Diagnostic and statistical manual of mental disorders ( $5^{\text {th }}$ edition). VA: American Psychiatric Publishing. 2013.

2. Bjork $B$, Ahlstrom $G$. The patient's perception of having recovered from an eating disorder. Health Care for Women International. 2008; 29: 926-944.

3. Cassin SE, Von Ranson K M. Personality and eating disorders: A decade in review. Clinical Psychology Review. 2005; 25: 895-916.

4. Nilsson K, Sundbom E, Haglof B. A longitudinal study of perfectionism in adolescent onset anorexia nervosa, restricting type. European Eating Disorders Review. 2008; 16: 386-394.

5. Cooper MJ, Deepak K, Grocutt E, Bailey E. The experience of 'feeling fat' in women with anorexia nervosa, dieting and non-dieting women: An exploratory study. European Eating Disorders Review. 2007; 15: 366-372.

6. Rodríguez MB, Hernández AP, Bouly RP. Anorexia nerviosa: Características y síntomas. Revista Cubana de Pediatria. 2007; 72: 300-305.

7. Kaye W. Neurobiology of anorexia and bulimia nervosa. Physiology \& Behavior. 2008; 94: 121-135.

8. Vindreau, C. Bulimia in psychiatric clinic. Brusset B, Couvreur C. Fine A editors. In: La boulimie. 2003; 81-102. 
9. Frosthlom L, Fink P, Christensen KS, Toft T, Ornbol E, Olesen F, et al. The patients' illness perceptions and the use of primary health care. Psychosomatic Medicine. 2005; 67: 997-1005.

10. Granato TM, Aiello-Vaisberg TMJ. Interactive narratives about infant care and its affective-emotional meanings. PsicologiaClínica. 2013; 25: 17-35

11. Tierney S, Fox JRE. Living with the anorexic voice: A thematic analysis Psychology and Psychotherapy: Theory, Research and Practice. 2010; 83 . 243-254.

12. Hoskins ML. Living research: the experience of researching self, other, and discourse. Journal of Constructivist Psychology. 2000; 13: 47-66.

13. Stake RE. Case studies. Denzin N, Lincoln $Y$ editors, In: Handbook of qualitative research. 2000; 236-247.

14. Guest G, Bunce A, Johnson L. How many interviews are enough?: An experiment with data saturation and variability. Field Methods. 2006; 18: 5982.

15. Maykut $\mathrm{P}$, Morehouse R. Beggining qualitative research: A philosophic and practical guide. Londres: Farmer Press Teacher's Library. 1994.

16. Braun V, Clarke V. Using thematic analysis in psychology. Qualitative Research in Psychology. 2006; 3: 77-101.

17. Limbert C. Perceptions of social support and eating disorder characteristics. Health Care for Women International. 2010; 31: 170-187.

18. Sluzki CE. The social network: Frontier of systemic practices. Barcelona: Gedisa. 1996.

19. Shea ME, Pritchard ME. Is Self-Esteem the Primary Predictor of Disordered Eating? Personality and Individual Differences. 2007; 42: 1527-1537.

20. Leonidas C, Santos MA. Body image and food habits in anorexia nervosa an integrative review of the literature. Psicologia: Reflexão e Crítica. 2012 23: $550-558$

21. Sweetingham R, Waller G. Childhood experiences of being bullied and teased in the eating disorders. European Eating Disorders Review. 2008; 16 401-407.
22. Leonidas C, Santos MA. Social support networks and eating disorders: An integrative review of the literature. Neuropsychiatric Disease and Treatment. 2014; 10: 915-927.

23. Shomaker LB, Furman W. Interpersonal influenceson late adolescentgirls and boys' disorderedeating. Eating Behaviors. 2009; 10: 97-106.

24. Karpowicz E, Skärsäter I, Nevonen L. Self-esteem in patients treated for anorexia nervosa. International Journal of Mental Health Nursing. 2009; 18 318-325.

25. Dimitropoulo, G, Carter J, Schachter R, Woodside DB. Predictors of family functioning in carers of individuals with anorexia nervosa. International Journal of Eating Disorders. 2008; 41: 739-747.

26. Kluck AS. Family factors in the development of disordered eating: Integrating dynamic and behavioral explanations. Eating Behaviors. 2008; 9: 471-483.

27. Marcos YQ, Cantero MCT. Assessment of social support dimensions in patients with eating disorders. The Spanish Journal of Psychology. 2009; 12 : 226-235

28. Soenens B, Vamsteenkiste M, Vandereycken W, Luyten P, Sierens E, Goossens L. Perceived parental psychological control and eating-disordered symptoms: Maladaptative perfectionism as a possible intervening variable. The Journal of Nervous and Mental Disease. 2008; 196: 144-152.

29. Bryant-Waugh R, Lask B. Eating disorders: An overview. Journal of Family Therapy. 1995; 17: 13-30.

30. Lane RC. Anorexia, masochism, self-mutilation, and autoerotism: The spider mother. Psychoanalitic Review. 1995; 89: 101-123.

31. Dallos R, Denford S. A qualitative exploration of relationship and attachment themes in families with an eating disorder. Clinical Child Psychology and Psychiatry. 2008; 13: 305-322.
Ann Nutr Disord \& Ther - Volume 4 Issue 1 - 2017

ISSN : 2381-8891 | www.austinpublishinggroup.com

Santos et al. (C) All rights are reserved
Citation: Leonidas C and dos Santos MA. Emotional Meanings Assigned to Eating Disorders: Narratives of Women with Anorexia and Bulimia Nervosa. Ann Nutr Disord \& Ther. 2017; 4(1): 1040. 